\title{
The Role of Pharmacist in the Health Care System: Current Scenario in India
}

Saurabh Nimesh *
Department of Pharmacology, Shri
Gopichand College of Pharmacy, Ahera,
Baghpat, Uttar Pradesh, India
*email: nimeshmiet@gmail.com
Keywords:
Education
Ethics
Graduate
Pharmacovigilance
Social

\begin{abstract}
Pharmacists are society's specialists on drugs. The Pharmacist of today is a drug-maker, drug-dispenser, drug-custodian, patient-counselor, drug-researcher, and drug-educator and above all an honest and patriotic citizen. The techno-proficient foundation of the drug expert gives him/her the certainty of providing services with a moral way to deal with the satisfaction of patients. The consecrated qualities are required to be cherished and professed by the pharmacist. Pharmacists assume a significant job in giving health care services, benefits through community pharmacy services in rural areas where physicians are not accessible or where physician services are unreasonably expensive for meeting the health care necessities. The paper at that point recognizes how pharmacists give expanded services, identifies key challenges and barriers, and suggests rules and regulations that could help secure open doors for pharmacists to play out an extended job.
\end{abstract}

Received: March 29th 2020

Accepted: May 7th 2020

Published: May 21 2020

(C) 2020 Saurabh Nimesh. Published by Institute for Research and Community Services Universitas Muhammadiyah Palangkaraya. This is an Open Access article under the CC-BY-SA License (http://creativecommons.org/licenses/by-sa/4.0/). DOI: https://doi.org/10.33084/bjop.v3i2.1325

\section{INTRODUCTION}

A pharmacist or drug expert is an individual who is engaged in designing, creating or manufacturing of a drug product, dispensing of a drug, managing, and planning of a pharmaceutical care plan (Abdelaziz et al., 2016). They are experts in the activity and use of drugs, including their chemistry, pharmacology, and the formulation of medicines. They are the health care professionals who have the responsibility to give essential consideration to the patients and giving protection and providing safe and effective use of medicines (Islam et al., 2016). The focal point of the profession of pharmacy has moved from technical, product-oriented, functions to patient-oriented, health outcomes counseling information and professional services (Toklu \& Hussain, 2013). This move by and large alluded to as 'Pharmaceutical care', humiliates the country that pharmacists, working in collaboration with other health care providers, undertake responsibility for patient outcomes with respect to their drug therapy (Tran et al., 2017).

The chief undertaking of a modern pharmacist is to identify, resolve and prevent drug-related issues (Ayalew et al., 2019). Some significant parts of health care are laid out in the report of the international conference on primary health care held in September 1978 at Alma Ata to achieve the goal 'Health for by 2000 A.D.' are (Kulczycki et al., 2017):

1. Education concerning prevailing health problems and methods of identifying, preventing and controlling them

2. Promotion of food supply and proper nutrition

3. Prevention and control of locally epidemic nutrition

4. Provision of essential diseases

5. Immunization against the major infection diseases 
6. Availability of health professionals and national health policies (Lam \& Sokn, 2019).

All the more ever this report was viewed as a basic requirement to be supplement as indicated by the economic and social estimations of the country and its public. The word HEALTH implies various things to various people groups from an alternate country (Odeh, et al., 2019). Such a large number of individuals only means opportunity from any infection or the absence of disease. According to the World health organization (WHO) 'Health is complete physical, mental and social well-being and not merely absence of disease' (Alhamoudi \& Alnattah, 2018).

The word pharmacy is derived from the word "Pharma". This word had first been used in the 15th to 17th century (Gomo et al., 2016). As per WHO, there are approximately 2.6 million pharmacists and other pharmaceutical personnel all over the world. Pharmacy is one of the popular fields among the students. Education in pharmacy varies from one country to another country. In India, the academic courses in the field of pharmacy start from diploma level to doctoral level as presented in Table I (DiPietro-Mager \& Farris, 2016).

Table I. Pharmacy courses (diploma to doctoral level) in India - A complete guidance

\begin{tabular}{|c|c|c|}
\hline Course & & Description \\
\hline $\begin{array}{l}\text { Diploma } \\
\text { Pharmacy }\end{array}$ & in & $\begin{array}{l}\text { Diploma in Pharmacy (D. Pharm.) admission } \\
\text { requirementsincludethat applicants must be at least } \\
17 \text { years of age at the time of admission and are } \\
\text { required to complete the Higher Secondary } \\
\text { Certificate (HSC) or Intermediate examin the science } \\
\text { stream. Required subjectsare physics, chemistry and } \\
\text { biology or mathematics. A minimum of } 40 \% \text { marks } \\
\text { is needed in each course. The fees for both Bachelor } \\
\text { of Pharmacy (B. Pharm.) and D. Pharm. is varies } \\
\text { based on institution (Croft et al., 2018). }\end{array}$ \\
\hline $\begin{array}{l}\text { Bachelor } \\
\text { Pharmacy }\end{array}$ & of & $\begin{array}{l}\text { B. Pharm. admission requirements are as follows: } \\
\text { applicants must be at least } 17 \text { years of age at the time } \\
\text { of admission and are required to complete the HSC } \\
\text { or Intermediate exam in the science stream. } \\
\text { Necessary subjects are biology/mathematics, } \\
\text { chemistry, and physics. Admission requirements } \\
\text { vary between institutions, so in order to be } \\
\text { considered a top candidate for admission, it is also }\end{array}$ \\
\hline
\end{tabular}

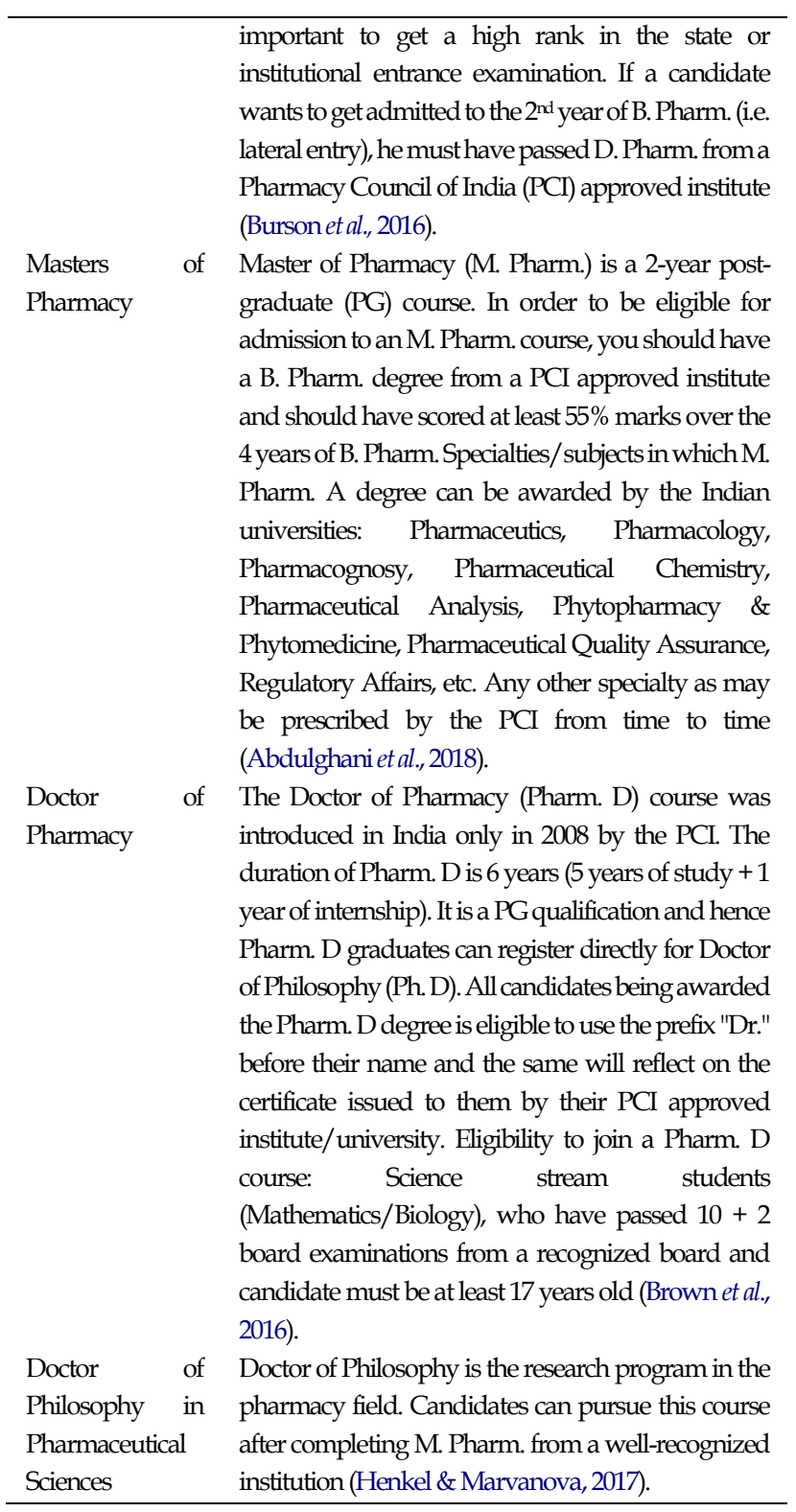

In general, professionals including health care systems in India are not much different from those in other countries, including:

1. Direct professionals: Pharmacist, Physician/surgeon, Nurse, Compounder, and Dispenser

2. Indirect professionals: Engineers, Teachers, Every person (Todd et al., 2015).

3. Different professionals play different minor roles in the health care system, but the only pharmacist plays a major role in the health care system (Saseen et al., 2017). 


\section{ROLES OF PHARMACIST}

The pharmacist is the bridge between a physician/surgeon and patients who counsel and advise the patient to maximize the desired effect of the drugs and minimize the untoward/adverse effects of the drug. The roles of the pharmacist in different sectors of the health care system is shown in Figure 1. Meanwhile, details of the role of the pharmacist in the different health sectors are presented in Table II (Introne \& Goggins, 2019; Minor et al., 2019).

\section{PHARMACIST}

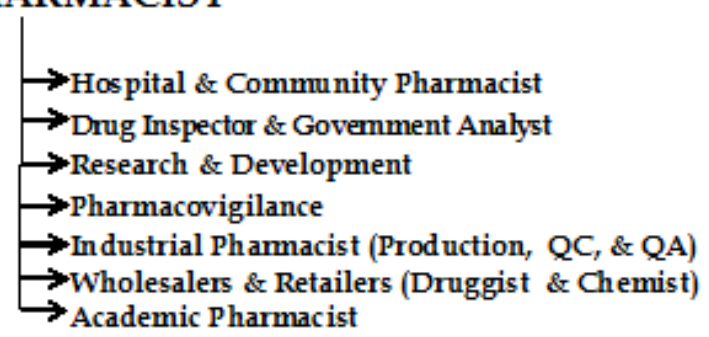

Figure 1. The roles of the pharmacist in different sectors of the health care system in India

Table II. The role of the pharmacist in the different health sectors in India

\begin{tabular}{ll}
\hline \multicolumn{1}{c}{ Sector } & \multicolumn{1}{c}{ Role } \\
\hline Pharmacovigilance & Pharmacist plays a vital role in medication \\
& safety monitoring. Pharmacists can be \\
& deployed to assist in monitoring the safe and \\
& effective use of available medicine, which \\
& certainly includes the management of adverse \\
& drug reactions. He worth-while information \\
& collected by the pharmacist in \\
& Pharmacovigilance should be appreciated. \\
& Pharmacists act as an open-arm to clinical \\
& expertise in the sharing of resources including \\
& databases. Pharmacistplaysanessential rolein \\
& developing communication materials like \\
& newsletters and other publications through \\
& the drug information and poison centers, \\
& whichare utilized by different professions and \\
& professionals for disseminating drug alerts \\
and other drug safety information (Kagashe et & al., 2017). \\
In academic pharmacists focus on teaching, \\
research, and training of the upcoming \\
pharmacist. Academic institute is a major \\
source of a pharmacist, who adds \\
professionals into the health care system. By \\
arranging a seminar, project, or system \\
academics, pharmacist plays a valuablerolein \\
the health care system. Education motivates
\end{tabular}

professionals in the health care system. From their basic education training and preregistration training, students acquire a broad understanding of the scientific principles and techniques of the pharmaceutical sciences and the ability to keep pace throughout their careers with developments in medicine and pharmacy (Brazeau et al, 2009).

Their knowledge and expertise extend to all aspects of the preparation, distribution, action, and uses of drugs and medicines as well as to enable those who wish to continue their studies to undertake PG training and research. Educational training programs help to professionals for their current knowledge. The pharmacist gets specialized knowledge regarding drugs and therapeutic action through there practical training. Overall, we can say academic pharmacist's preliminary partin the pharmacy profession (Nguyen etal., 2019).

Hospital

Pharmacists

Hospital pharmacists are a vital part of the healthcare team. Working in either the government or private hospitals, being a hospital pharmacist means the part of a team where the focus is firmly on patients. Hospital pharmacists are responsible for monitoring the supply of all medicines used in the hospital and are in charge of purchasing, manufacturing, dispensing and quality testing their medication stock along with help from pharmacy assistants and pharmacy technicians (Kelling et al., 2016).

Community Community pharmacist jobs would be all Pharmacists about helping the public, assessing their condition and making the decision about which medicines they should take. They will be involved in dispensing medicine and offering patient advice and practical help on keeping health. It is a very responsible job and community pharmacists tend to be highly respected members of their communities (Dalton \& Byrne, 2017).

Community pharmacists are also taking on more of the clinical roles that have traditionally been undertaken by a physician, such as the management of asthma and diabetes as well as blood pressure testing. They also help people give up smoking, alter their diets to make them healthier and advice on sexual health matters. Some community pharmacists own their own business and enjoy the challenges of financial management and responsibility for staff, stock and premises that this brings. Other work for large high street pharmacy chain and have the opportunity to move around within an established company structure (Hermansyah et al., 2016).

Primary Care These are people work for National health Pharmacist/ service organizations that are in charge of a range of local. Theirjob is to ensure the best use 


\begin{tabular}{ll}
\hline Prescribing & $\begin{array}{l}\text { of medicines and resources across the area. In } \\
\text { Advisors }\end{array}$ \\
Some places, practice pharmacist or primary \\
care pharmacist also run medication review \\
Clinics and have lots of patient contacts \\
(Dalton \& Byrne, 2017). \\
Research \& $\quad \begin{array}{l}\text { Pharmacist contributes to research and their } \\
\text { expertise in formulation development is of } \\
\text { particular relevance to the biological } \\
\text { availability of active ingredients (Khan et al., } \\
\text { 2011). } \\
\text { The pharmacist, whose professional ethics } \\
\text { demand a concern for the interest of patients, } \\
\text { can make a contribution to proper marketing } \\
\text { practices related to health care and to the } \\
\text { provision of appropriate information to health } \\
\text { professionals and the public (Casalino et al., } \\
\text { 2018). }\end{array}$ \\
\hline
\end{tabular}

\section{CONCLUSION}

In a quickly developing health care services framework with expanded requests for results and customized care, the pharmacist is a critical partner in the provision of care. The range of abilities of the pharmacist gives a unique opportunity to convey the ideal medicine usage to oversee intense and chronic diseases just as numerous different roles. The various roles of Pharmacists in various segments of the pharmacy profession, like Industrial, academics, community health, clinical research, drug design, discovery and development of new molecules, etc. The paper features the present situation of the pharmacy profession in the various health care frameworks. The pharmacist is a backbone that reinforces the health care framework. At last, pharmacists are responsible for ensuring that 'Right drug to the right patient at the right time in the right dose through the right route in the right way'. With the goal that pharmacists are a basic piece of the health care framework.

\section{ACKNOWLEDGMENT}

The authors would like to acknowledge Dr. Md. Iftekhar Ahmad and Rubi Rani for a critical review of the manuscript.

\section{REFERENCES}

Abdelaziz, H. Al Anany, R., Elmalik, A., Saad, M., Prabhu, K., Al-Tamimi, H., Salah, S.A., \& Cameron, P. (2016). Impact of clinical pharmacy services in a short stay unit of a hospital emergency department in Qatar. International Journal of Clinical Pharmacy, 38(4), 776-779. doi:10.1007/s11096-016-0290-9

Abdulghani, K.H., Aseeri, M.A., Mahmoud, A., \& Abulezz, R. (2018). The impact of pharmacistled medication reconciliation during admission at tertiary care hospital. International Journal of Clinical Pharmacy, 40(1), 196-201. doi:10.1007/s11096-017-0568-6

Alhamoudi, A. \& Alnattah, A. (2018). Pharmacy education in Saudi Arabia: The past, the present, and the future. Currents in Pharmacy Teaching and Learning, 10(1), 54-60. doi:10.1016/j.cptl.2017.09.014

Ayalew, M.B., Solomon, L., \& Abay, S. (2019). Pharmaceutical Care Practice in Community and Institutional Drug Retail Outlets of Gondar Town, North West Ethiopia. Global Advances in Health and Medicine, 8, 2164956119868777. doi:10.1177/2164956119868777

Brazeau, G.A., Meyer, S.M., Belsey, M., Bednarczyk, E.M., Bilic, S., Bullock, J., DeLander, G.E., Fiese, E.F., Giroux, S.L., McNatty, D., Nemire, R., Prescott, W.A., \& Traynor, A.P. (2009). Preparing Pharmacy Graduates for Traditional and Emerging Career Opportunities. American Journal of Pharmaceutical Education, 73(8), 157. doi:10.5688/aj7308157

Brown, T.J., Todd, A., O'Malley, C., Moore, H.J., Husband, A.K., Bambra, C., Kasim, A., Sniehotta, F.F., Steed, L., Smith, S., Nield, L., \& Summerbell, C.D. (2016). Community pharmacy-delivered interventions for public health priorities: a systematic review of interventions for alcohol reduction, smoking cessation, and weight management, including meta-analysis for smoking cessation. BMJ Open, 6(2), 009828. doi:10.1136/bmjopen-2015009828

Burson, R.C., Buttenheim, A.M., Armstrong, A., \& Feemster, K.A. (2016). Community pharmacies as sites of adult vaccination: a 
systematic review. Human Vaccines and Immunotherapeutics, 12(12), 3146-3159. doi:10.1080/21645515.2016.1215393

Casalino, G., Castiello, C., Del Buono, N., \& Mencar, C. (2018). A framework for intelligent Twitter data analysis with non-negative matrix factorization. International Journal of Web Information Systems, 14(3), 334-356. doi:10.1108/IJWIS-11-2017-0081

Croft, H., Gilligan, C., Rasiah, R., Levett-Jones, T., \& Schneider, J. (2018). Thinking in pharmacy practice: a study of community pharmacists' clinical reasoning in medication supply using the think-aloud method. Pharmacy, 6(1), 12-18. doi:10.3390/pharmacy6010001

Dalton, K. \& Byrne, S. (2017). Role of the pharmacist in reducing healthcare costs: current insights. Integrated Pharmacy Research and Practice, 6, 3746. doi:10.2147/IPRP.S108047

DiPietro-Mager, N.A. \& Farris, K.B. (2016). The Importance of Public Health in Pharmacy Education and Practice. Indian Journal of Pharmaceutical Education and Research, 80(2), 7688. doi:10.5688/ajpe80218

Gomo, C.O., Ogunleye, J., \& Portlock, J. (2016). Strategies enhancing the public health role of community pharmacists: a qualitative study. Journal of Pharmaceutical Health Services Research, 7(2), 97104. doi:10.1111/jphs.12131

Henkel, P.J., \& Marvanova, M. (2017). Rural Disparities in Alzheimer's Disease-Related Community Pharmacy Care in the United States. Journal of Rural Health, 34(4), 347-358. doi:10.1111/jrh.12279

Hermansyah, A., Sainsbury, E., \& Krass, I. (2016). Community pharmacy and emerging public health initiatives in developing Southeast Asian countries: a systematic review. Health and Social Care in the Community, 24(5), 11-22. doi:10.1111/hsc.12289

Introne, J. \& Goggins, S. (2019). Advice reification, learning, and emergent collective intelligence in online health support communities. Computers in Human Behavior, 99, 205-218. doi:10.1016/j.chb.2019.05.028

Islam, M.A., Khan, S.A., Sunaseelan, S., \& Talukder, R. (2016). Specialty education for student pharmacist and Pharm D graduates in U.S. colleges and schools of pharmacy. Currents in Pharmacy Teaching and Learning, 8(2), 184-190. doi:10.1016/j.cptl.2015.12.001

Kagashe, I., Yan, Z., \& Suheryani, I. (2017). Enhancing Seasonal Influenza Surveillance: Topic Analysis of Widely Used Medicinal Drugs Using Twitter Data. Journal of Medical Internet Research, 19(9), 315. doi:10.2196/jmir.7393

Kelling, S.E., Rondon-Begazo, A., DiPietro-Mager, N.A., Murphy, B.L., \& Bright, D.R. (2016). Provision of clinical preventive services by community pharmacists. Preventing Chronic Disease, 13(1), 160232. doi:10.5888/pcd13.160232

Khan, M.F.O., Deimling, M.J., \& Philip, A. (2011). Medicinal Chemistry and the Pharmacy Curriculum. American Journal of Pharmaceutical Education, 75(8), 161. doi:10.5688/ajpe758161

Kulczycki, A., Wensel, T.M., \& Hogue, M. (2017). Practices, challenges, and opportunities for improving pneumococcal immunization in working-age, at-risk adults through community pharmacies. Infectious Diseases in Clinical Practice, 25(1), 23-28. doi:10.1097/IPC.0000000000000452

Lam, S.W., \& Sokn, E. (2019). Effect of Pharmacy-Driven Bedside Discharge Medication Delivery Program on Day 30 Hospital Readmission. Journal of Pharmacy Practice, 897190019825961. doi:10.1177/0897190019825961

Minor, S., Huffman, M., Lewis, P.R., Kost, A., \& Prunuske, J. (2019). Community preceptor perspectives on recruitment and retention: The COPPRR study. Family Medicine, 51(5), 389398. doi:10.22454/FamMed.2019.937544

Nguyen, M.T., Tran, V.C., Nguyen, X.H., \& Nguyen, L.M. (2019). Web document summarization by exploiting social context with matrix cofactorization. Information Processing and Management, 56(3), 495-515. doi:10.1016/j.ipm.2018.12.006

Odeh, M., Scullin, C., Flemin, G., Scott, M.G., Horne, R., \& McElnay, J.C. (2019). Ensuring continuity of patient care across the healthcare interface: Telephone follow-up post-hospitalization. British Journal of Clinical Pharmacology, 85(3), 616-625. doi:10.1111/bcp.13839 
Saseen,J.J., Ripley, T.L., Bondi, D., Burke, J.M., Cohen, L.J., McBane, S., McConnell, K.J., Sackey, B., Sanoski, C., Simonyan, A., Taylor, J., \& Griend, J.P.V. (2017). ACCP clinical pharmacist competencies. Pharmacotherapy: The Journal of Human Pharmacology and Drug Therapy, 37(5), 630-636. doi:10.1002/phar.1923

Todd, A., Copeland, A., Husband, A., Kasim, A., \& Bambra, C. (2015). Access to all areas? An arealevel analysis of the accessibility to general practice and community pharmacy services in England by urbanity and social deprivation. BMJ Open, 5(5), 007328. doi:10.1136/bmjopen2014-007328

Toklu, H.Z. \& Hussain, A. (2013). The changing face of pharmacy practice and the need for a new model of pharmacy education. Journal of Young Pharmacists, $\quad 5(2), \quad 38-40$. doi:10.1016/j.jyp.2012.09.001

Tran, T., Khattar, S., Vu, T.T., Potter, M., Hodding, J., Kuo, G.M., \& Le, J. (2017). Impact of pharmacist discharge counseling on hospital readmission and emergency department visit. Journal of Hospital Administration, 6(2), 61-68. doi:10.5430/jha.v6n2p68 